\title{
Possibility of derivation of energetic state variables from simplified BWR thermal state equation for water and water steam
}

\author{
Magda Vestfálová ${ }^{1, *}$ \\ ${ }^{1}$ KEZ, TU Liberec, Studentská 1402/2, 46117 Liberec 1, Czech Republic
}

\begin{abstract}
Thermal equation of state, along with the basic heat capacities are the most important documents needed to description the behavior of substances. Any other thermodynamic properties of a substance can already be deduced from these relations. The aim of this paper is to derive the dependence of energetic properties of water steam on the temperature and density from simple thermal equation of state based on original BWR thermal equation of state which describes the behavior of $\mathrm{H}_{2} \mathrm{O}$ in the gaseous phase in region of usual pressures and temperatures with sufficient accuracy.
\end{abstract}

\section{Introduction}

Water and water vapor are commonly found in nature. Moreover, they are substances which are frequently used in various technical devices. Therefore, it is necessary to know the properties and behavior of the substance. Properties of water and steam are thoroughly investigated, measured and tabulated in great detail [1]. Research of properties of water and water steam began to organize on an international level since 1929 to provide reliable and consistent data on their properties. In 1972 there was founded the International Association for the Properties of Water and Steam - IAPWS which deals with verification and interpolation of experimental data and with expressing of the thermodynamic and transport properties of water and steam. In 1995, there was accepted Pruß - Wagner equation as the international formulation of thermodynamic properties of water and steam for scientific purposes IAPWS-95 [2]. The equation is valid for the liquid and gas in a wide range of temperatures and pressures. It contains a large number of constants. International Standards properties of water and steam for example [3] are based on Scientific formulation IAPWS-95.

In many routine technical cases, there is more appropriate to use some "simple" equation for calculation of thermodynamic properties of water steam. "Simple" form of thermal equation of state will be applicable only on a limited range of temperatures and pressures, and its accuracy will be less.

In 1940 Manson Benedict, G. B. Webb and L. C. Rubin constructed "simple" so called original Benedict - Webb - Rubin (hereinafter BWR) thermal equation of state [4].

$$
\begin{gathered}
p=r T \rho+r T \rho^{2} B_{0}+r T \rho^{3} b- \\
-A_{0} \rho^{2}-a \rho^{3}+a \alpha \rho^{6}-\frac{\rho^{2} C_{0}}{T^{2}}+ \\
+\frac{c \rho^{3}}{T^{2}}\left(1+\gamma \rho^{2}\right) e^{-\gamma \rho^{2}} .
\end{gathered}
$$

There is some physical basics of BWR equation in the state behavior of gases. Equation contains an addition to the specific gas constant $r$ still eight parameters: $A_{0}, B_{0}$, $C_{0}, a, b, c, \alpha$ and $\gamma$, that characterize the individual properties of the gas. They must be determined from experimental dates by regression. So, as well as other multi-parameter equations, BWR equation can be only used to description of properties of substances for which there is sufficient amount of experimental data in wide range of pressures and temperatures. This requirement is fulfilled for water and water steam undoubtedly.

The original BWR equation was suggested for calculation of behavior of hydrocarbons. For these substances values obtained from BWR equation are very close to the experimental date [5]. For these substances BWR equation describes the behavior of materials in single phase areas (it is in superheated steam and in the super cooled liquid) very well. In heterogeneous areas (below the limit curve), as expected, there is a local maximum and a local minimum and the results can not be explained by equilibrium thermodynamics. Parameters of BWR equation for hydrocarbons are presented for example in work [6] too.

In [7] there was shown the using of BWR thermal equation of state for $\mathrm{H}_{2} \mathrm{O}$. There was described derivation of the isochoric specific heat capacity and enthalpy from the thermal equation BWR. It has been shown that in the area where the error of the $p-v-T$ values obtained from BWR thermal state equations is small, the values of enthalpy, calculated from the relation derived 
using equation BWR are sufficiently precise too. The disadvantage is that the application area (the area with small errors) is very small and the equations for isochoric heat capacity and enthalpy is still quiet difficult.

In [8] there was found that in BWR thermal equation of state there can by neglected some members and for suitable values of constants of the new, more simple thermal equation of state we can obtain the $p-v-T$ values with reasonable accuracy, it means the deviation of the values obtained from equation and tabulated data according to formulation for scientific purposes IAPWS95 is less than $1 \%$.

The aim of this paper is to derive the equations for calculation enthalpy and entropy from simple thermal state equation derived in [8] and to control the accuracy of these values in comparison with the tabulated data according to formulation for scientific purposes IAPWS95 [2].

\section{Equation of state}

In [8] there was derived for water vapor a simplified BWR equation in the form

$$
\begin{aligned}
p= & r T \rho+r T \rho^{2} B_{0}+r T \rho^{3} b- \\
& -A_{0} \rho^{2}-a \rho^{3}-\frac{\rho^{2} C_{0}}{T^{2}} .
\end{aligned}
$$

This equation gives for routine engineering calculations sufficiently accurate results. When we use simplified BWR equation with coefficients derived for water steam, we can calculate the properties of water vapor to a state of beginning of condensation until the pressure about $15 \mathrm{MPa}$ (temperature about $340^{\circ} \mathrm{C}$ ). For high temperatures, equation can be used for even higher pressures (see Figure 1.), but not more than probably $30 \mathrm{MPa}$.

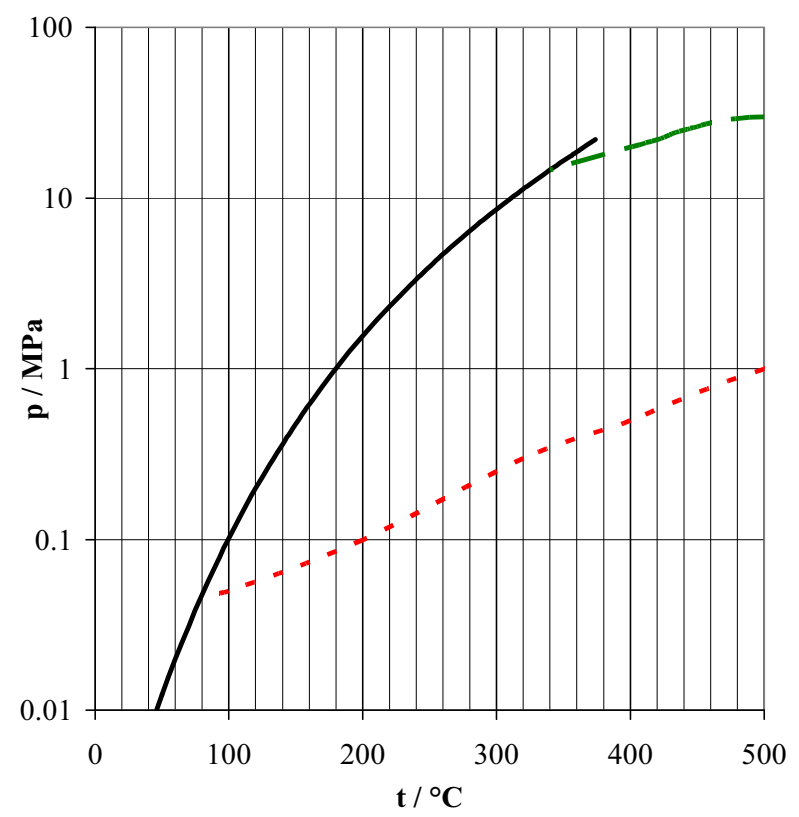

Fig. 1. The area of applicability of the different models for calculation of state properties of $\mathrm{H}_{2} \mathrm{O}$ with the accuracy to $1 \%$ : thick line - the limit curve; red dotted line - limit of applicability of ideal gas model; green dashed line - limit of applicability of simplified BWR equation [11].

The fundamental problem while using BWR equation for water and steam is that the critical point is not captured correctly: critical point under BWR equation is in the $p-v$ diagram shifted significantly "to the right", i.e. to the higher values of specific volumes (less densities) and the "up", i.e. to the higher pressures, and is located on the higher isotherm than are the corresponding real values. The limit curve constructed using BWR equation

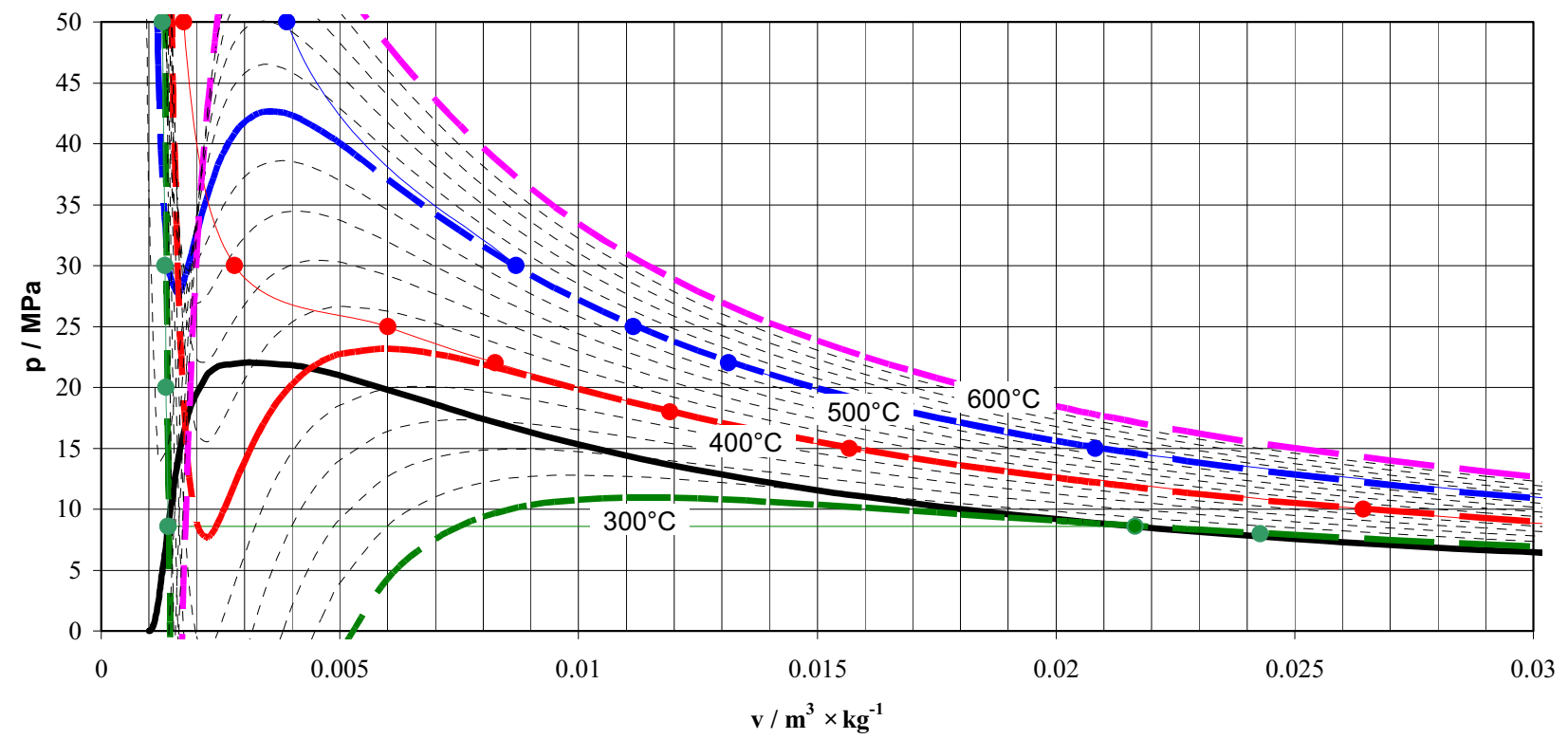

Fig. 2. Isotherms of simplified BWR equation [8] for $\mathrm{H}_{2} \mathrm{O}: 300^{\circ} \mathrm{C}, 400^{\circ} \mathrm{C}, 500^{\circ} \mathrm{C}$ a $600^{\circ} \mathrm{C}$ (thick dashed lines) and theirs comparison with real isotherms according to IAPWS'95 data (points). 
would be in the phase $p$ - $T$ diagram extended to a higher values of pressures and temperatures, the curve would continue beyond the real critical condition even further. In the $p-v$ diagram would be the limit curve constructed from BWR equation shifted "to the right and up" from the real limit curve. Therefore we can use the BWR equation for water and water steam in the single-phase field - in the gas phase (the behavior of liquid phase does not coincide with the results obtained from BWR equation) and at greater distances from the critical point. The results obtained from the new simplified equation (without correction terms with coefficients " $c$ " and " $\gamma$ ") have for a lower temperature the similar variation of limit curve as BWR equation, moreover, for temperatures greater than about $500^{\circ} \mathrm{C}$ and high densities the results are totally unrealistic. For very high pressures equation can not be used either for high temperatures (see Figure 2.).

\section{The dependence of the specific heat capacity on the volume of a substance described by simplified BWR equation}

The dependence of isochoric specific heat capacity on the volume can be obtained from the thermal equation of state [7] by the following procedure:

$$
\begin{aligned}
\left(\frac{\partial c_{V}}{\partial v}\right)_{T} & =\left\{\frac{\partial}{\partial T}\left[T\left(\frac{\partial p}{\partial T}\right)_{V}-p\right]\right\}_{V}= \\
& =T\left(\frac{\partial^{2} p}{\partial T^{2}}\right)_{V} .
\end{aligned}
$$

Partial derivatives $\left(\frac{\partial p}{\partial T}\right)_{V}$ and $\left(\frac{\partial^{2} p}{\partial T^{2}}\right)_{V}$ we obtain from the simplified BWR equation (4) as

$$
\left(\frac{\partial p}{\partial T}\right)_{V}=\rho r+\rho^{2} r B_{0}+\rho^{3} r b+\frac{2 \rho^{2} C_{0}}{T^{3}}
$$

and

$$
\left(\frac{\partial^{2} p}{\partial T^{2}}\right)_{V}=\left[-\frac{6 \rho^{2} C_{0}}{T^{4}}\right]
$$

and so

$$
\left(\frac{\partial c_{V}}{\partial v}\right)_{T}=T\left(\frac{\partial^{2} p}{\partial T^{2}}\right)_{V}=-\frac{6 \rho^{2} C_{0}}{T^{3}} .
$$

The dependence of isochoric specific heat capacity on the temperature and volume we can obtain by integration the relation (8) over the volume between "known" and the current state. The "known" state: the state at $v \rightarrow \infty$, i.e. $p \rightarrow 0$, it is the idealized state, for which the specific heat capacity does not depend on volume, but only on the temperature [9]

$$
\begin{gathered}
c_{V}(T, v)=c_{V}^{i d}(T)+\int_{\infty}^{v}\left(\frac{\partial c_{V}}{\partial v}\right)_{T} d v= \\
=c_{V}^{i d}(T)+\int_{\infty}^{v} T\left(\frac{\partial^{2} p}{\partial T^{2}}\right)_{V} d v= \\
=c_{V}^{i d}(T)+\int_{\infty}^{v}\left[-\frac{6 \rho^{2} C_{0}}{T^{3}}\right] d v= \\
=c_{p}^{i d}(T)-r+\frac{6 \rho C_{0}}{T^{3}} .
\end{gathered}
$$

To illustrate the applicability of the above equation, we show (Figure 3) calculated courses of the isochoric specific heat capacities on temperature for $\mathrm{H}_{2} \mathrm{O}$ for pressures (from top to bottom): 20MPa, 10MPa, $1 M P a$, $0.1 \mathrm{MPa}$ and $611.657 \mathrm{~Pa}$. As the values of isobaric specific heat capacity in the "idealized state" $c_{p}^{i d}(T)$ we used the values at a pressure 611.657 $\mathrm{Pa}$ according to [3]. As in the previous case, the experimentally

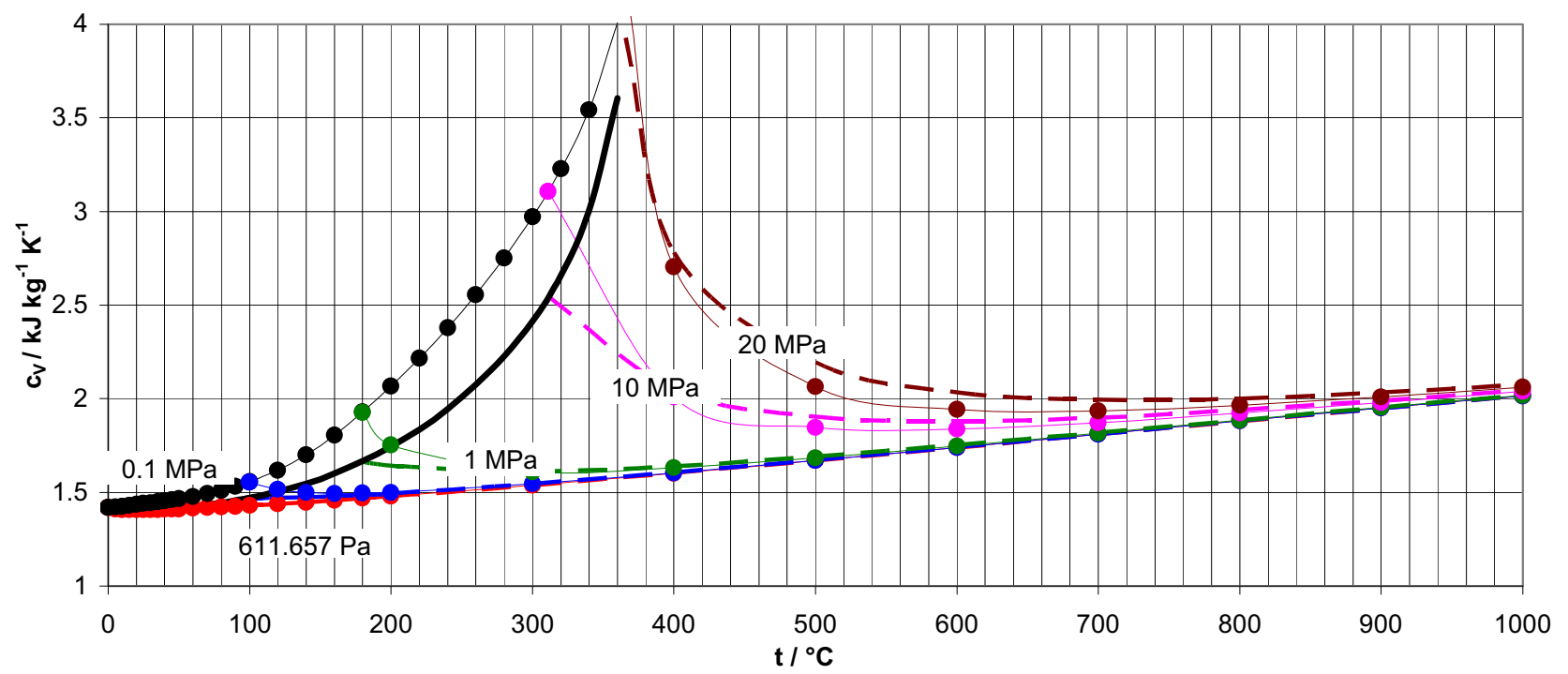

Fig. 3. Dependence of the isochoric heat capacity of $\mathrm{H}_{2} \mathrm{O}$ on the temperature for pressures: $611.657 \mathrm{~Pa}$ (red), $0.1 \mathrm{MPa}$ (blue), $1 \mathrm{MPa}$ (green), 10MPa (purple) and 20MPa(brown) for real substance - comparison of results according simplified BWR equation (4) (thick dashed lines) and according IAPWS'95 data (points on the thin lines). 


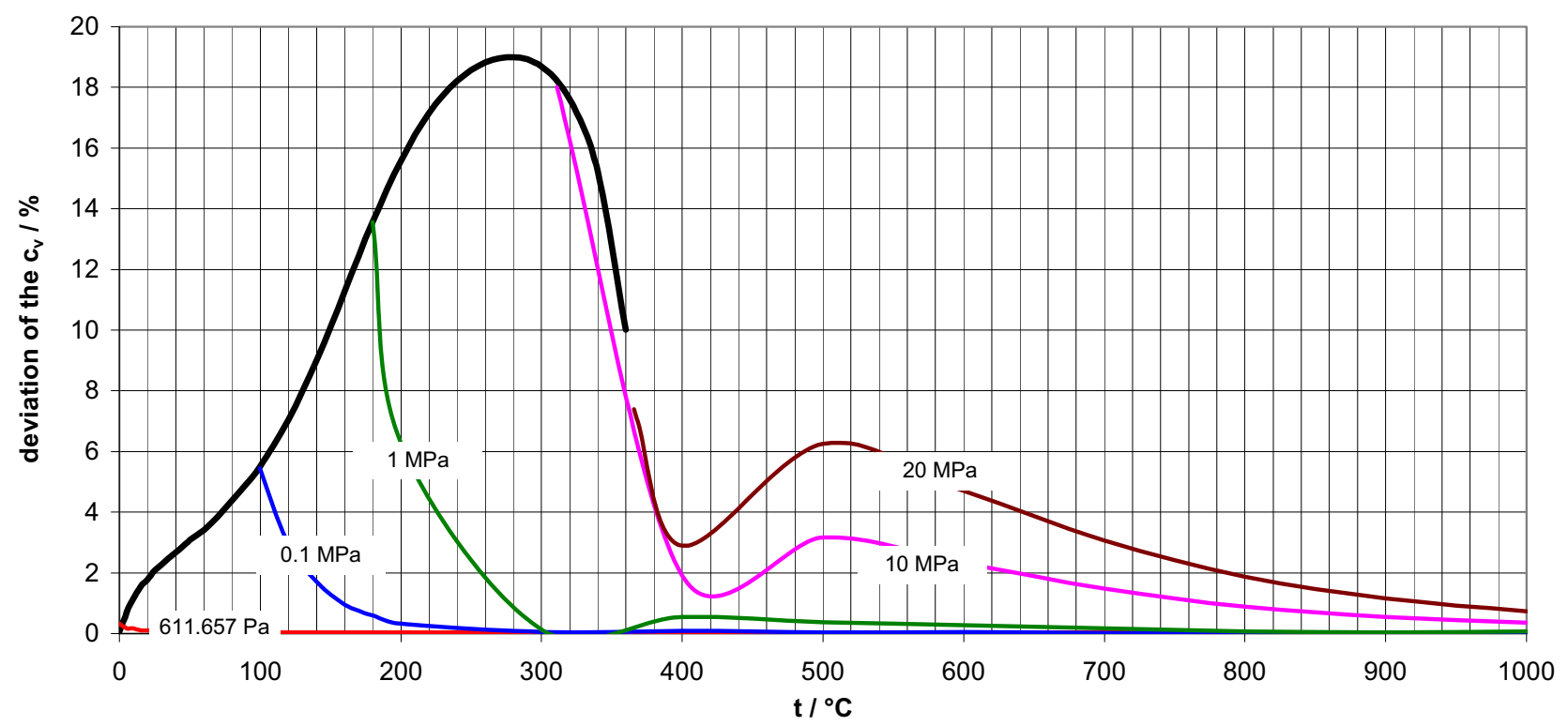

Fig. 4. Deviation of the calculated values of isochoric heat capacity of $\mathrm{H}_{2} \mathrm{O}$ from IAPWS' 95 data in percentage for pressures: 611.657 Pa, 0.1MPa, 1MPa, 10MPa, 20MPa.

determined course [3] is also plotted (circle points on the thin lines) and the limit curve is indicated in the diagram, too. Again, it is a nice match in locations distant from the limit boundary curve. But near the boundary curve the calculated values are far from IAPWS'95 data even in the pressures and temperatures in which $p$ - $v$ - $T$ dates obtained from the simplified BWR equation show a good agreement with IAPWS'95 data.

Figure 4 shows the deviation of the calculated values of isochoric specific heat capacity from IAPWS'95 data in percentage.

The deviations of isochoric specific heat capacities calculated from equation derived from a simplified BWR state equation are too large even for low values of pressures.

\section{Energy values}

An important quantity in the calculation of the processes taking place in technical equipment is the enthalpy. Because we are working with state equation which was derived from BWR equation, it means with the state equation of the physical type, we will work again with the enthalpy depending on the temperature and volume. We will use the relation [7]

$$
\begin{gathered}
d h(T, v)=c_{V} d T+v\left(\frac{\partial p}{\partial T}\right)_{V} d T+ \\
+v\left(\frac{\partial p}{\partial v}\right)_{T} d v+T\left(\frac{\partial p}{\partial T}\right)_{V} d v
\end{gathered}
$$

Partial derivatives $\left(\frac{\partial p}{\partial v}\right)_{T}$ and $\left(\frac{\partial p}{\partial T}\right)_{V}$ it is possible to obtain from the simplified BWR equation (4):

$$
\begin{gathered}
\left(\frac{\partial p}{\partial v}\right)_{T}=-T \rho^{2} r-2 T \rho^{3} r B_{0}- \\
-3 T \rho^{4} r b+2 A_{0} \rho^{3}+3 a \rho^{4}+\frac{2 \rho^{3} C_{0}}{T^{2}} .
\end{gathered}
$$

The derivation $\left(\frac{\partial p}{\partial T}\right)_{V}$ was derived previously (6).

The dependence of enthalpy on the temperature and volume is obtained by integration the relation (10) between "known" and the current state over the volume and temperature. As in the case of specific heat capacity, it is chosen as the "known" state the idealized state $(v \rightarrow$ $\infty, p \rightarrow 0$, so the enthalpy does not depend on volume, but only on the temperature [12]) and the temperature at which we know the value of the enthalpy $\left(T_{0}\right)$

$$
\begin{gathered}
h(T, v)=h_{T_{0}}^{\infty}+\int_{T_{0}}^{T}\left[c_{V}^{i d}(T)+v^{i d}\left(\frac{\partial p}{\partial T}\right)_{V}^{i d}\right] d T+ \\
+\int_{\infty}^{v}\left[v\left(\frac{\partial p}{\partial v}\right)_{T}+T\left(\frac{\partial p}{\partial T}\right)_{V}\right] d v .
\end{gathered}
$$

Due to the large errors in the calculation of isochoric specific heat capacity from the relation, which was derive from our state equation, we will integrate the equation (23) only over the volume and we will use as the "known" state the dependence of enthalpy on temperature for " $v \rightarrow \infty, p \rightarrow 0$ ", practically the values of enthalpy at a pressure of $611.657 \mathrm{~Pa}$ according IAPWS'95 date:

$$
\begin{gathered}
h(T, v)=h^{\infty}(T)+ \\
+\int_{\infty}^{v}\left[v\left(\frac{\partial p}{\partial v}\right)_{T}+T\left(\frac{\partial p}{\partial T}\right)_{V}\right] d v
\end{gathered}
$$




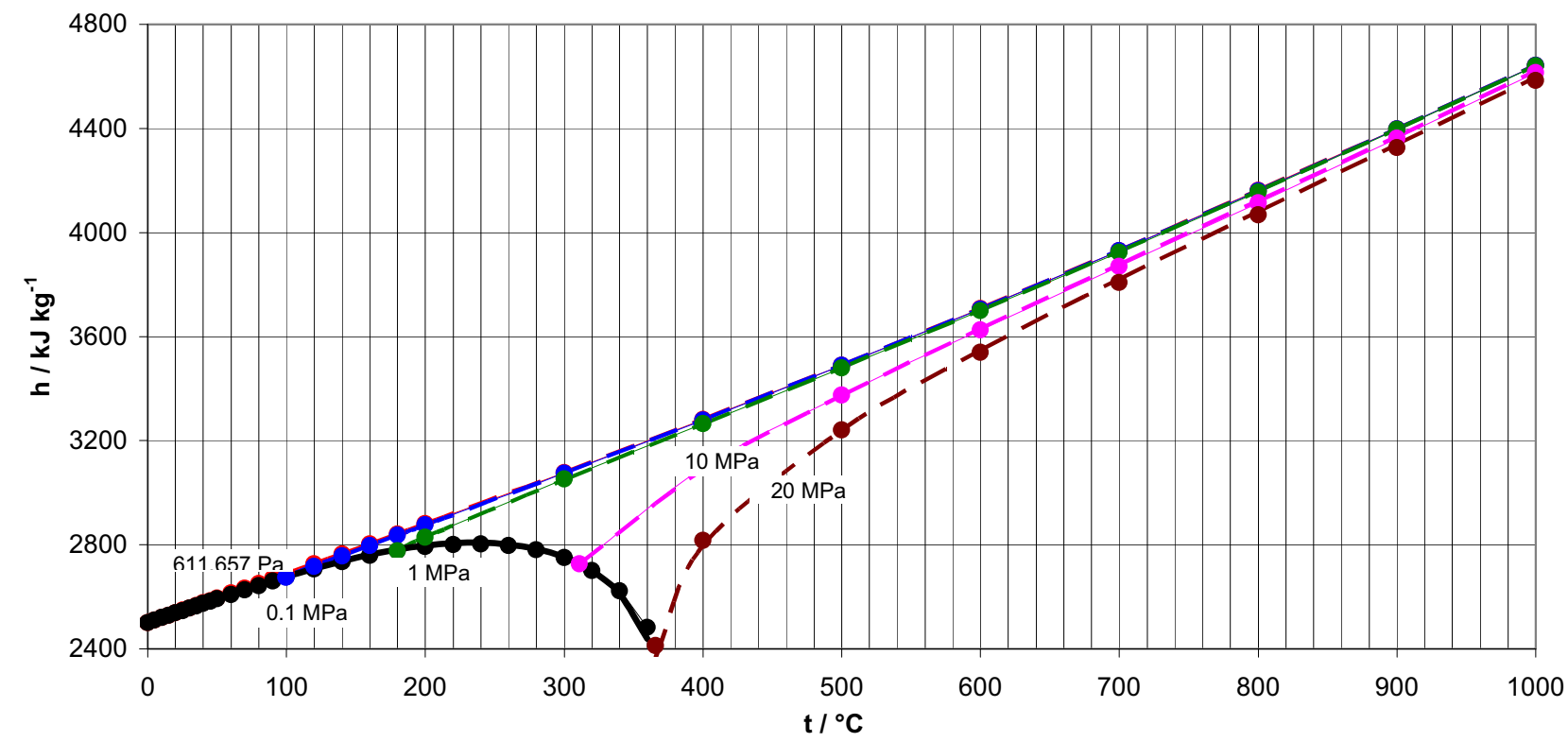

Fig. 5. Dependence of the enthalpies of $\mathrm{H}_{2} \mathrm{O}$ on the temperature for pressures: 611.657 $\mathrm{Pa}, 0.1 \mathrm{MPa}, 1 \mathrm{MPa}, 10 \mathrm{MPa}, 20 \mathrm{MPa}$ comparison of results according simplified BWR equation (26) (thick dashed lines) and according IAPWS'95 data (points on thin lines).

Substituting the partial derivatives (13) and (25) [12]

$$
\begin{aligned}
h(T, v)= & h^{\infty}(T)+\rho\left[r T B_{0}-2 A_{0}-\frac{4 C_{0}}{T^{2}}\right]+ \\
& +\frac{\rho^{2}}{2}[2 r T b-3 a] .
\end{aligned}
$$

To illustrate the applicability of the above equation, see on Figure 5 calculated courses of the enthalpies on temperature for $\mathrm{H}_{2} \mathrm{O}$ for pressures (from the button to the top): 20MPa, 10MPa, $1 \mathrm{MPa}, 0.1 \mathrm{MPa}$ and $611.657 \mathrm{~Pa}$. As the values of enthalpy "idealized state" $h^{\infty}(T)$ we took values at a pressure $611.657 \mathrm{~Pa}$ according to [3].
As in the previous case, the experimentally determined course [3] is also plotted (circle points on the thin lines) and the limit curve is indicated in the diagram, too. In case of enthalpy, there is a very nice match of the calculated values with IAPWS'95 data even on the boundary curve.

Figure 6 shows the deviation of the calculated values of enthalpies from IAPWS'95 data in percentage.

The deviations of enthalpies calculated from equation derived from a simplified BWR state equation are very small even for the values on the boundary curve. The significant error occurs only near the critical point.

Now, let's derive the relationship for the absolute value of entropy.

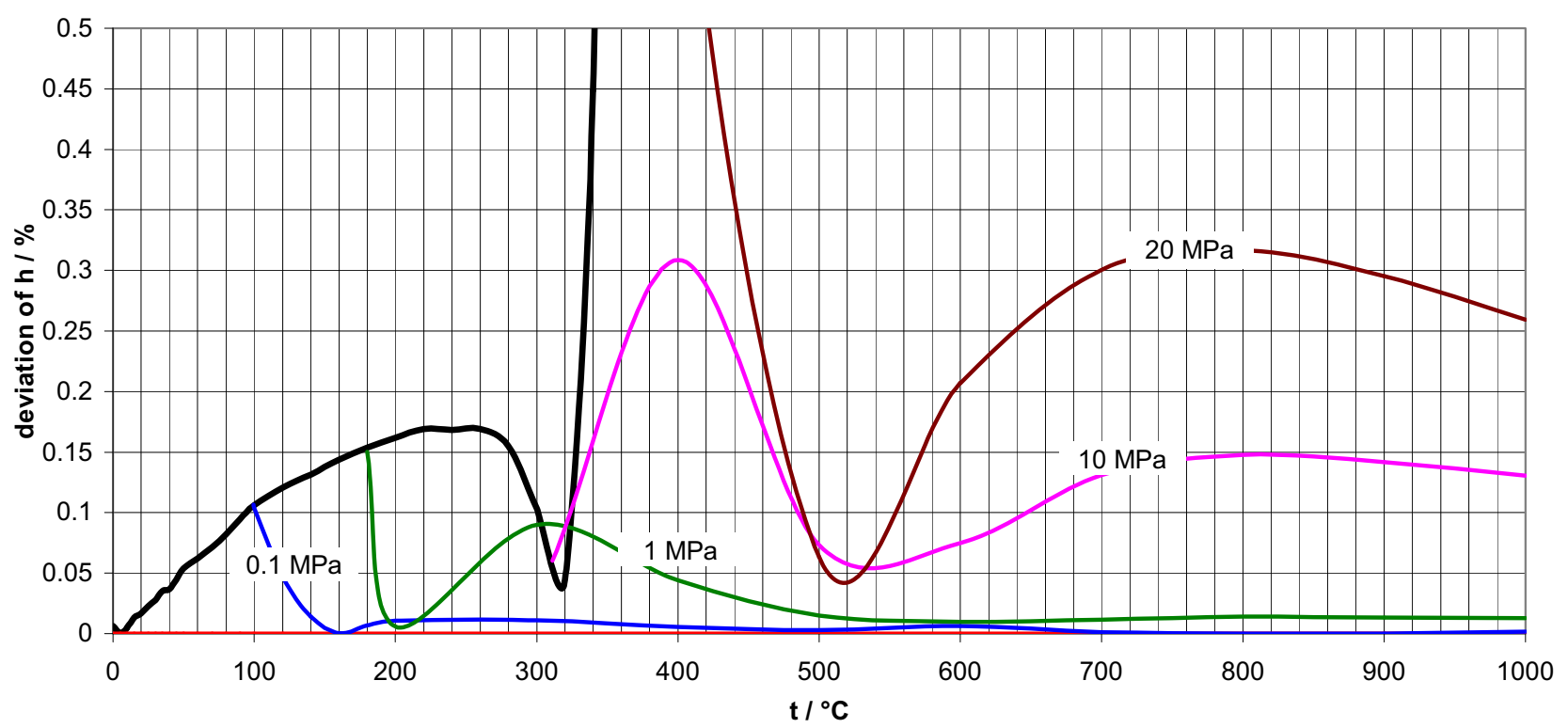

Fig. 6. Deviation of the calculated values of enthalpies of $\mathrm{H}_{2} \mathrm{O}$ from IAPWS'95 data in percentage for pressures: $611.657 \mathrm{~Pa}$, $0.1 \mathrm{MPa}, 1 \mathrm{MPa}, 10 \mathrm{MPa}, 20 \mathrm{MPa}$. 
The full differential of entropy we can write the usual way as

$$
d s(T, v)=\left(\frac{\partial s}{\partial T}\right)_{v} d T+\left(\frac{\partial s}{\partial v}\right)_{T} d v
$$

The first member on the right hand side we can express by comparison of the Gibbs equation

$$
d u=T d s+p d v
$$

with the total differential of the internal energy as the function of characteristic independent variables

$$
d u(T, v)=\left(\frac{\partial u}{\partial s}\right)_{v} d s+\left(\frac{\partial u}{\partial v}\right)_{s} d v
$$

The first partial derivation of internal energy with respect to entropy at constant volume is

$$
\left(\frac{\partial u}{\partial s}\right)_{v}=T
$$

its second order partial derivation

$$
\left(\frac{\partial^{2} u}{\partial s^{2}}\right)_{v}=\left(\frac{\partial T}{\partial s}\right)_{v}=\frac{T}{c_{v}} .
$$

The second member on the right hand side we can express using Maxwell equation

$$
\left(\frac{\partial s}{\partial v}\right)_{T}=\left(\frac{\partial p}{\partial T}\right)_{v}
$$

So, the total differential of entropy it is possible to write as

$$
d s(T, v)=\left(\frac{c_{V}}{T}\right) d T+\left(\frac{\partial p}{\partial T}\right)_{v} d v .
$$

The dependence of entropy on the temperature and volume is obtained by integration the relation (21) between "known" and the current state over the volume and temperature. As in the case of specific heat capacity and enthalpy, it is chosen as the "known" state the idealized state: $v \rightarrow \infty, p \rightarrow 0$, so the entropy does not depend on volume, but only on the temperature [9] (practically the state with "very low" pressure: $\left.p_{0}=611.657 \mathrm{~Pa}, v=v_{0}\right)$ and at temperature at which we know the value of the entropy $\left(T_{0}\right)$ :

$$
\begin{gathered}
s(T, v)=s_{T_{0}}^{0}+\int_{T_{0}}^{T}\left[\frac{c_{V}^{i d}(T)}{T}\right] d T+ \\
+\int_{v_{0}}^{v}\left[\left(\frac{\partial p}{\partial T}\right)_{V}^{i d}\right] d v+\int_{v}^{\infty}\left[\left(\frac{\partial p}{\partial T}\right)_{V}^{i d}\right] d v+ \\
+\int_{\infty}^{v}\left[\left(\frac{\partial p}{\partial T}\right)_{V}^{B W R}\right] d v .
\end{gathered}
$$

The first term on the right hand side is the known value of entropy at the temperature $T_{0}$ and volume $v_{0}$. The second member expresses the deviation of entropy in an idealized state of gas when the temperature changes from $T_{0}$ to general temperature $T$. We can use the Mayer equation to its expression. The third member is a deviation of entropy along the ideal isotherm between the state of the volume $v_{0}$ and the state of the general

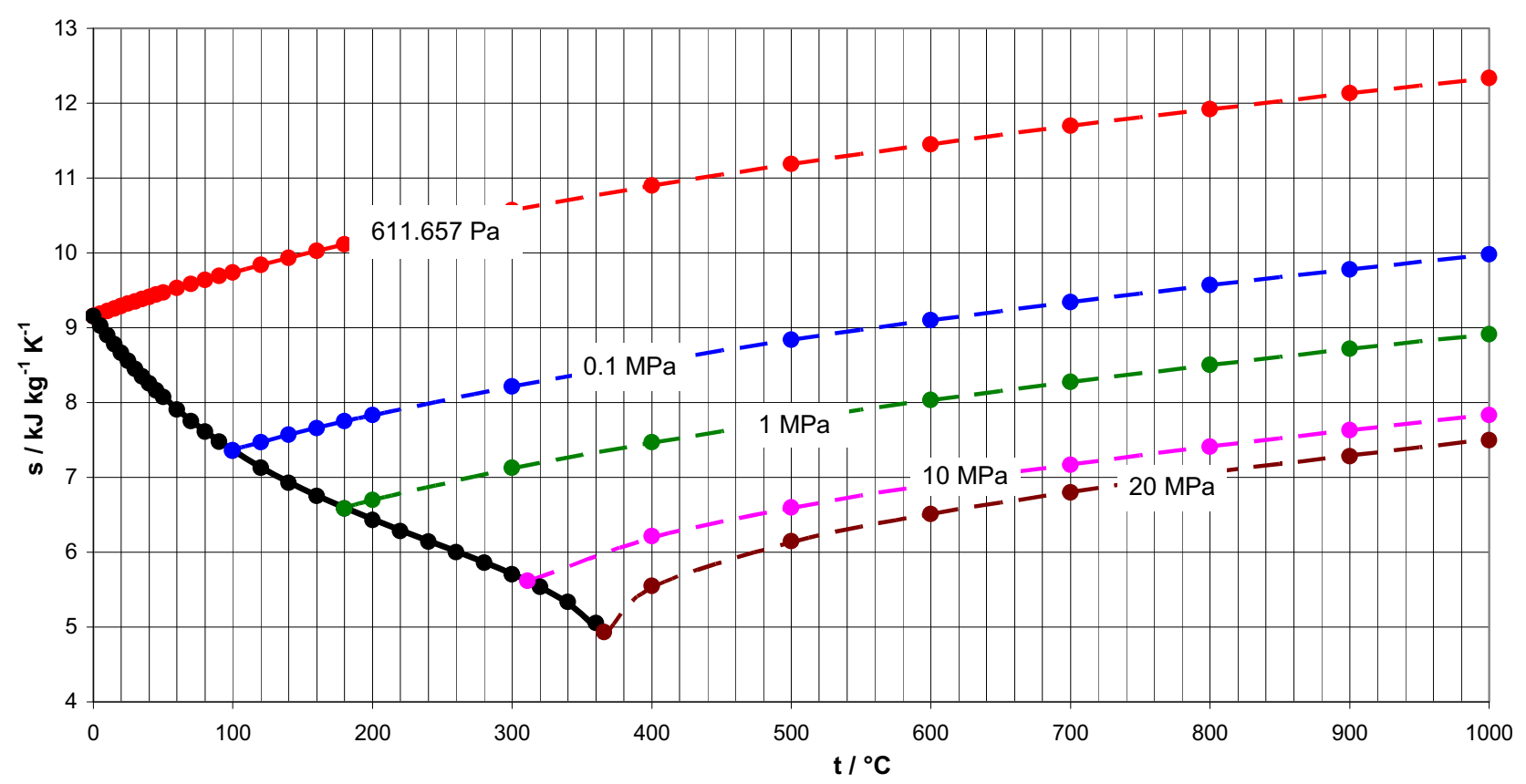

Fig. 7. Dependence of the entropies of $\mathrm{H}_{2} \mathrm{O}$ on the temperature for pressures: 611.657 $\mathrm{Pa}, 0.1 \mathrm{MPa}, 1 \mathrm{MPa}, 10 \mathrm{MPa}, 20 \mathrm{MPa}$ comparison of results according simplified BWR equation (29) (thick dashed lines) and according IAPWS'95 data (points on thin lines). 
volume $v$. To its expression we use the ideal gas state equation. The fourth member is a deviation of the entropy along the ideal isotherm between the state of the general volume $v$ and the state where $v \rightarrow \infty$, it is a state where the ideal isotherm coincides with the real isotherm. To its expression we use again the ideal gas state equation. The last member is the deviation of entropy between the state, where $v \rightarrow \infty$, and the actual real state:

$$
\begin{gathered}
s(T, v)=s_{T_{0}}^{0}+\int_{T_{0}}^{T}\left[\frac{c_{p}^{i d}(T)}{T}\right] d T- \\
-r \ln \frac{T}{T_{0}}+r \ln \frac{v}{v_{0}}+ \\
+\int_{\infty}^{v}\left[-\frac{r}{v}+\left(\frac{\partial p}{\partial T}\right)_{V}^{B W R}\right] d v .
\end{gathered}
$$

Due to the large errors in the calculation of isochoric specific heat capacity from the relation, which was derive from our state equation, we will integrate the equation (26) only over the volume and we will use as the "known" state the dependence of entropy on temperature for " $v \rightarrow \infty, p \rightarrow 0$ ", practically the values of entropy at a pressure of $611.657 \mathrm{~Pa}$ according IAPWS'95 date:

$$
\begin{aligned}
& s(T, v)=s^{0}(T)+r \ln \frac{v}{v_{0}}+ \\
& +\int_{\infty}^{v}\left[-\frac{r}{v}+\left(\frac{\partial p}{\partial T}\right)_{V}^{B W R}\right] d v .
\end{aligned}
$$

After substituting the partial derivative of pressure with temperature at constant volume for BWR equation (13), integration and adjustments we obtain [9]

$$
\begin{aligned}
& s(T, v)=s^{0}(T)+r \ln \frac{p_{0}}{\rho r T}- \\
& -\rho\left(r B_{0}+\frac{2 C_{0}}{T^{3}}\right)-\frac{b r \rho^{2}}{2} .
\end{aligned}
$$

To illustrate the applicability of the above equation, we show (Figure 7) calculated courses of the entropies on temperature for $\mathrm{H}_{2} \mathrm{O}$ for pressures (from the button to the top): 20MPa, 10MPa, $1 \mathrm{MPa}, 0.1 \mathrm{MPa}$ and 611.657 Pa.

As in the previous cases, the experimentally determined course [3] is also plotted (circle points on the thin lines) and the limit curve is indicated in the diagram, too. In case of entropy, there is a very nice match of the calculated values with IAPWS'95 data even on the boundary curve. The significant error occurs only near the critical point, too.

Figure 8 shows the deviation of the calculated values of entropies from IAPWS'95 data in percentage.

\section{Conclusions}

When calculating isochoric specific heat capacity of $\mathrm{H}_{2} \mathrm{O}$ in the gaseous state according to the equation derived from a simplified BWR equation [8] the errors are large in the low-pressure area too. So, it is unusable approach for practical calculations of the properties of water vapor. Conversely, a simplified BWR equation of state can be used with sufficient accuracy to the derivation and calculation of energy values, resp. theirs dependence on the volume. If we start from the real value of the enthalpy and entropy of $\mathrm{H}_{2} \mathrm{O}$ at low pressure (in a state

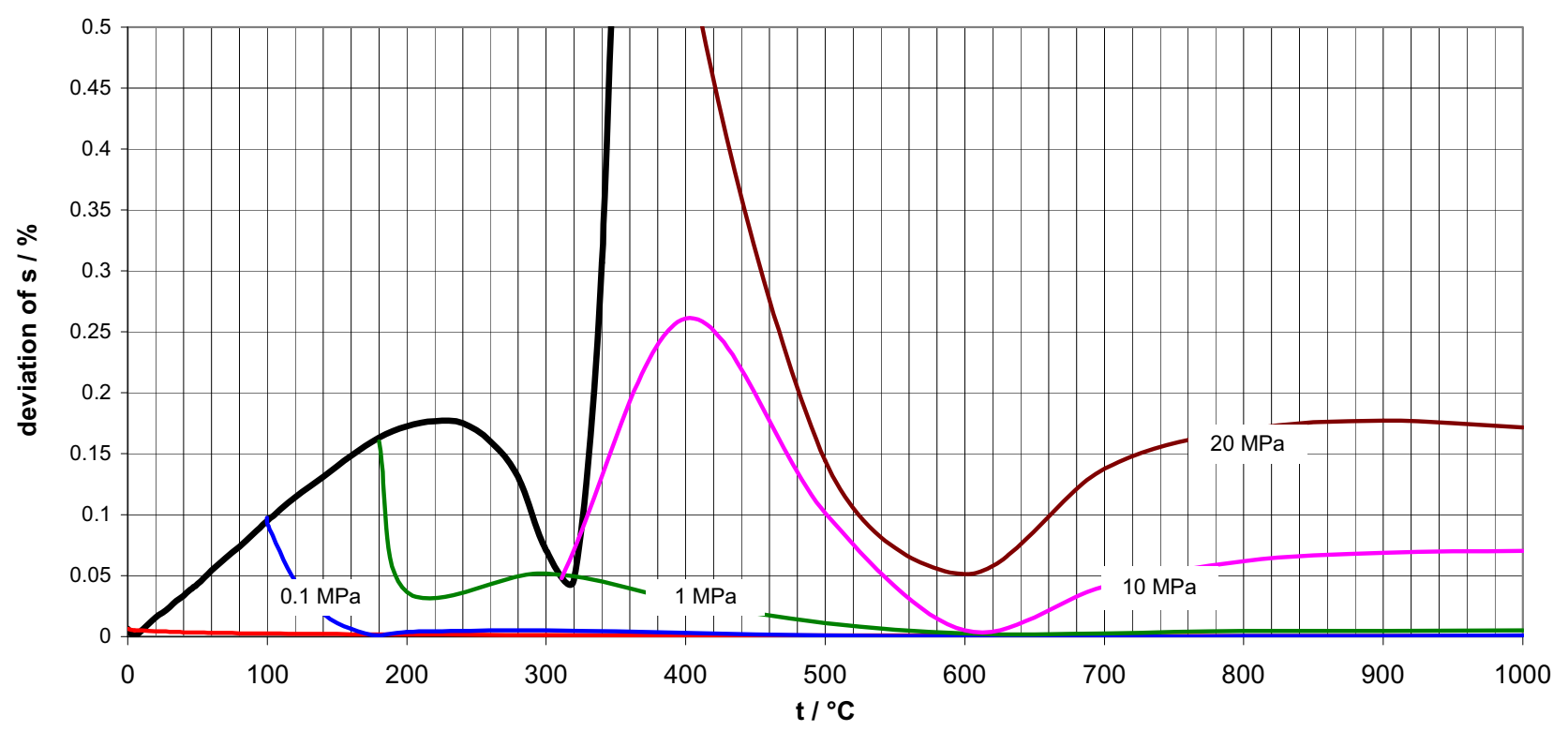

Fig, 8. Deviation of the calculated values of entropies of $\mathrm{H}_{2} \mathrm{O}$ from IAPWS'95 data in percentage for pressures: $611.657 \mathrm{~Pa}, 0.1 \mathrm{MPa}$, $1 M P a, 10 M P a, 20 M P a$. 
approaching to "idealized state") we can use the simple formulas (26) and (29) derived from the simplified BWR equation of state (4) for the practical calculation their values at higher pressures successfully. The calculated values are sufficiently precise to a state of beginning of condensation until the pressure about $15 \mathrm{MPa}$ (temperature about $340^{\circ} \mathrm{C}$ ).

\section{Acknowledgment}

This publication was written at the Technical University of Liberec, Faculty of Mechanical Engineering with the support of the Institutional Endowment for the Long Term Conceptual Development of Research Institutes, as provided by the Ministry of Education, Youth and Sports of the Czech Republic in the year 2016.

\section{References}

1. M.Vestfálová, P.Šafařík, Experimental Fluid Mechanics (2015)

2. W.Wagner, A.Pruß, The IAPWS Formulation 1995 for the Thermodynamic Properties of Ordinary Water Substance for General and Scientific Use, Journal of Physical and Chemical Reference Data, 31: 387-535 (2002)

3. O.Šifner, J.Klomfar, Mezinárodni standardy termofyzikálních vlastnosti vody a vodni páry, (1996)

4. M. Benedict, G. Webb, L. C. Rubin, Journal of Chemical Physics 10 (12): 747-758 (1942)

5. M. Benedict, G. Webb, L. C. Rubin, Chemical Engineering Progress (CEP) 47 (8): 419-422 (1951)

6. J. Novák, Termodynamické vlastnosti plynů, (2007)

7. M. Vestfálová, Experimental Fluid Mehcanics (2014)

8. M.Vestfálová, M.Petř́íková, Experimental Fluid Mechanics (2015)

9. I. Středa, Stavová rovnice BWR a termodynamické vlastnosti relných plynů a jejich směsí, (1987) 